\title{
Knowledge transfer performance of multinational companies
}

\author{
Pedersen, Torben; Petersen, Bent; Sharma, D. Deo
}

Document Version

Final published version

Publication date:

2002

License

CC BY-NC-ND

Citation for published version (APA):

Pedersen, T., Petersen, B., \& Sharma, D. D. (2002). Knowledge transfer performance of multinational companies.

Link to publication in CBS Research Portal

\section{General rights}

Copyright and moral rights for the publications made accessible in the public portal are retained by the authors and/or other copyright owners and it is a condition of accessing publications that users recognise and abide by the legal requirements associated with these rights.

\section{Take down policy}

If you believe that this document breaches copyright please contact us (research.lib@cbs.dk) providing details, and we will remove access to the work immediately and investigate your claim. 


\title{
Knowledge Transfer Performance of Multinational Companies
}

\author{
Torben Pedersen ${ }^{1} \bullet$ Bent Petersen ${ }^{1} \bullet$ Deo Sharma ${ }^{2}$ \\ Department of International Economics and Management ${ }^{1}$ and Department of Marketing, ${ }^{2}$ \\ Copenhagen Business School, Howitzvej 60, $2^{\text {nd }}$ floor, 2000 F, Denmark \\ tp.int@cbs.dk•bp.int@cbs.dk・ds.marketing@cbs.dk
}

\begin{abstract}
Knowledge is ascribed a key role when explaining the existence and the growth of multinational companies (MNCs). The effective dissemination throughout the MNC organization of valuable knowledge acquired by its local affiliates is seen as an important source of competitive advantage. Knowledge differs in characteristics and so do the available transfer mechanism. As such, it is essential that the MNC employs the mechanism of transfer that suits the specific knowledge characteristics. The use of unsuitable transfer mechanisms may cause loss of knowledge in the process of transmission or may involve unnecessarily high communication costs - both with potentially negative effects on the performance of the MNC. Focusing on internationalization knowledge this large-scale empirical study explores the incidence and the performance implications of fit between knowledge characteristics and transfer mechanisms as used by Danish MNCs. It is found that a substantial proportion of the observed MNC knowledge transfer transactions may be classified as 'misfits' and to some extent do these 'misfits' result in impaired performance of the MNCs.
\end{abstract}

(Knowledge Transfer, Knowledge Characteristics, Multinational Companies) 


\section{Introduction}

To an increasing extent is the success of multinational companies (MNCs) considered to be contingent upon the ease and speed by which valuable knowledge is disseminated throughout the organization (Hedlund 1986, Bartlett/Ghoshal 1989, Gupta/Govindarajan 1991). Thus, creation of knowledge in the spatially dispersed multinational organization is a necessary, but not sufficient condition for success in the global marketplace. If valuable knowledge remains in, or only diffuses slowly from, the individual MNC affiliates, opportunities for worldwide leverage are lost. Therefore, appropriate incentive structures and proper knowledge transfer mechanisms should be in place ensuring swift dissemination to other units of the multinational organization. It is essential that the MNC employs a medium suiting the specific characteristics of the knowledge subject to transfer. The use of unsuitable transfer mechanisms may cause loss of knowledge in the transmission process or may involve unnecessarily high communication costs - both with potentially negative effects on the overall performance of the organization.

It is an open question to what extent MNCs managers are capable of realizing the right 'fit' between, on the one side, the characteristics of the knowledge, and - on the other side - the medium, or mechanism, by which the knowledge is transferred. The combination of knowledge characteristics and transfer mechanism represents an important choice that is expected to have severe implications for performance. This study explores the knowledge transfer processes as they take place in Danish MNCs. Our focus will be on transfer of one specific type of knowledge, namely internationalization knowledge, i.e. knowledge that enables the organization to expand its activities across national borders. Internationalization knowledge includes a broad range of knowledge of conducting international operations, such as knowledge of customer preferences, supply structure, business culture, and industry standards in foreign markets.

As far as we know, our study is the first one to explore empirically the performance consequences of different combinations of knowledge characteristics and transfer mechanisms including both appropriate and inappropriate combinations - as made by MNCs. In a research field where empirical studies are in short supply, as ascertained by Simonin (1999), the study 
may contribute to the advancement of the field of knowledge transfer of MNCs in a more normative and practically oriented direction.

The paper is structured as follows: In the second section (following this introduction) we review the literature on knowledge transfer in the context of MNCs and internationalization processes of firms. The retrospective literature review reveals a theoretical development from almost complete neglect of the knowledge transfer as a process of its own to the current outspoken interest in knowledge transfer and its effects on MNC performance. Section three outlines the conceptual model of the study and develops research hypotheses. Section four reports the empirical analysis, including methodology, presentation of sample data, results and discussion of statistical tests. Conclusions and managerial implications make up section five.

\section{Literature Review on Knowledge Transfer in MNCs}

The literature on intra-organizational knowledge transfer has proliferated over the last two decades and today a large body of literature exists (for an overview, see Argote 1999). We will therefore restrict ourselves to a review of $\mathrm{MNC}$ literature that includes knowledge transfer aspects. At least three distinct streams of literature that specifically deal with knowledge transfer in multinational companies (MNCs) can be identified. These are: (1) literature on the internationalization process of firms, (2) literature on factors that facilitate or impede knowledge transfer of MNCs, and (3) Management-oriented literature on the use of transfer mechanisms in MNCs. The three literature streams seem to be converging in these years, but at their outset in the 1970s significant differences prevailed in terms of their approach to knowledge transfer in MNCs.

\subsection{Importance of Experiential Knowledge in the Internationalization Process}

Knowledge plays a central role in the internationalization process theory that explains firms' incremental international expansion (Carlson 1975, Bilkey/Tesar 1977, Johanson/Vahlne 1977). Based on the behavioral theory of the firm (Cyert/March 1963, Aharoni 1966) the theory 
describes firms' international expansion as a trial-and-error-based learning process: “... international expansion is inhibited by the lack of knowledge about markets and such knowledge can mainly be acquired through experience from practical operations abroad" (Forsgren/Johanson 1992, p. 10). As they gain local market knowledge firms expand internationally through a series of gradual investments.

Following Penrose (1959) the internationalization process theory distinguishes between objective knowledge and experiential knowledge. Objective knowledge is explicit (e.g. market data, legislation, export technicalities) and can be traded in the market. A critical assumption of the theory is that objective knowledge is of minor importance in the internationalization process of firms. It is first of all the on-going acquisition of experiential knowledge that determines the gradual commitment in the internationalization process. Knowledge of the market, the clients, the problems and the opportunities abroad are acquired by operating in the foreign market. It is through interaction with specific clients and other market actors that firms accumulate experiential knowledge. Consequently, the problems and opportunities intrinsic to a certain market and specific customers will primarily be discovered by those who are working in that market, e.g. people in the sales subsidiary or some other front-line unit. The internationalization process theory sees the individuals as holders of knowledge and emphasizes the idiosyncratic nature of experiential knowledge. Referring to Penrose (1959) the internationalization process theorists maintain that "experience itself can never be transmitted, it produces a change frequently a subtle change - in individuals and cannot be separated from them" (Johanson/Vahlne 1977, p. 30).

Furthermore, the possibility of transforming experiential knowledge into objective knowledge, i.e. the process through which tacit skills and knowledge are made explicit, is not recognized in the theory. Accordingly, the intra-organizational transfer of experiential knowledge from one affiliate to another can only take place through rotation of the individuals who possess the knowledge. But the transfer of knowledge is not only futile; it is also pointless to the extent that the crucial knowledge is market-specific: knowledge about how to do business in foreign market $\mathrm{A}$ is of little use in foreign market B. 
Thus, three characteristics are intrinsic to the experiential knowledge deemed pivotal by the internationalization process theory: (1) it is acquired and possessed by individuals, (2) it is context-specific (market-specific), and (3) it is not codifiable. Taken together, these characteristics make the transfer of knowledge almost a non-issue in the internationalization process theory. In other words, there is limited scope for organizational learning in the theory and decision-making is almost absent in relation to knowledge management issues like articulation and transfer of knowledge.

\subsection{The MNC as a Superior Vehicle for Knowledge Transfer}

The path-breaking conceptual and empirical studies of Zander (1991), Kogut/Zander (1992, 1993), and Zander/Kogut (1995) completely reverse this view by focusing on capabilities of knowledge transfer in MNCs. The very reason why MNCs exist is that they are efficient vehicles for creating and transferring knowledge across borders (Kogut/Zander 1993). In particular the capabilities of transferring tacit knowledge across borders distinguish the MNCs from the purely domestic firms. To a certain extent tacit knowledge can be codified, i.e. transformed into explicit knowledge. Codification of tacit knowledge facilitates the transfer process, but at the same time increases the risk of uncontrolled dissemination of firm-specific, proprietary knowledge. Thus, a trade-off exists between, on the one hand, incurred costs of communication and, on the other hand, assumed risk of knowledge dissemination, i.e. making the knowledge more susceptible to competitors' imitation. The internalization of business transactions holds the potential of changing this codification trade-off. First, as Kogut/Zander (1993) point out, internalization enables efficient transfer of tacit knowledge. Secondly, as Hedlund (1994) argues, internalization facilitates the knowledge codification process: "To a large extent [organizations] are 'articulation machines', built around codified practices and deriving some of their competitive advantages from clever, unique articulation." (Hedlund 1994: 76). The insights of Kogut, Zander, and Hedlund pull in the direction of making knowledge creation, knowledge characteristics and codification of (tacit) knowledge the central issues. Still, the knowledge management focus of these scholars is the decision of codification of strategic knowledge - rather than the managerial task of finding the proper fit between knowledge characteristics and transfer mechanism. Implicitly, knowledge characteristics and transfer mechanisms are supposedly interrelated to the extent that the two variables are inseparable. 
More recently, several scholars have brought attention to various organizational or environmental factors that facilitate, or impede, the transfer of knowledge across (multinational) organizations.

Teece (1977) found that the principal factors determining the transfer of knowledge are the degree of previous experience of transferring knowledge of firms, the cost of transfer, the age of the technology, and the number of firms using similar technology. Davidson/McFetridge (1985) found that transfer to unaffiliated firms is promoted if the firms have transferred knowledge in past. The development of knowledge transfer routines demands repetition that again requires standardization of the transfer process. Kogut/Zander (1992) found that firms with experience of knowledge transfer developed efficient procedures for codifying and transferring tacit knowledge. Another finding was that over a period of time firm-specific knowledge becomes less tacit and more codifiable. Simonin (1999) found that experience with particular partner firms eases subsequent transfer of marketing knowledge to these partners. He also found that general experience in knowledge transfer was an important facilitator.

Szulanski (1996) explored 'internal stickiness' of knowledge, i.e., factors that impede the intrafirm transfer of knowledge. He identified two sets of factors that impede the internal transfer of knowledge: motivational factors and knowledge-related factors. The former is related to the motivation of the subsidiary manager(s) to devote the necessary time and resources for conducting the transfer. The latter stem from the tacit, context-specific and ambiguous nature of certain knowledge. Furthermore, Szulanski points out that motivation to acquire and receive knowledge is important since new knowledge may disrupt current organizational practices and working routines. According to Szulanski (1996) knowledge acquisition and reception may require substantial investments in time and effort.

Transfer of knowledge is influenced by the socio-cultural and institutional distance between the foreign country and the home country of the MNC (Adler 1995). Knowledge in firms is contingent on their socio-cultural environment (Hofstede 1984): what is appropriate knowledge in one country may not suit the needs of firms in other countries. In turn, this may cause problems to the knowledge transfer process. Factors such as different language, business culture, 
and institutional framework make up a 'psychic distance' as perceived by the MNC manager (Johanson/Vahlne 1977). As the psychic distance between nations increases it is more difficult for firms to acquire knowledge from abroad (Mowery et al. 1996). Thus, a clash between national cultures may jeopardize the international transfer of knowledge. Furthermore, several studies suggest that geographical proximity is positively associated with knowledge transfer (Galbraith 1990, Lester/McCabe 1993, Epple et al. 1996).

\subsection{Knowledge Transfer mechanism}

In contrast to the positive theories of MNCs the management-oriented MNC literature is dominated by studies of knowledge transfer mechanisms rather than knowledge characteristics and knowledge codification. In a seminal study Keegan (1974) seeded an interest for the knowledge transfer media used by MNC executives. Keegan addressed the question of MNCmanagers' information sources in terms of transfer mechanisms. In his study of information sources utilized by headquarters executives in multinational companies Keegan found that written media (documentary sources such as reports and letters) were of much less importance than oral communication, including face-to-face communication. In a more recent study of managers' use of communication media in 14 multinational companies de Meyer (1991) found that face-to-face communication made up an important part of oral communication, and the emergence of new telecommunication technology did not seem to have changed this. Thus, telephone conversations, tele- and videoconferencing, etc., complements - but does not substitute for - face-to-face communication. Ghoshal et al. (1994) found that informal networking activities - such as direct contact among managers through joint work in teams, task forces, etc. - were the main determinants of knowledge flows in MNCs. In their influential contribution to the field of multinational management Bartlett/Ghoshal (1989) outline different knowledge transfer mechanisms used by MNCs in their pursuit of 'transnational strategies'.

\section{Conceptual Model and Development of Hypotheses}

The conceptual model of the study seeks to establish the relationships between: (A) the characteristics of the internationalization knowledge as acquired by the $\mathrm{MNC}$, (B) the 
mechanisms, or media, employed by the $\mathrm{MNC}$ in order to transfer the acquired internationalization knowledge across the organization, and $(\mathrm{C})$ the performance implications to the knowledge transfer operation and the subsequent knowledge application in the MNC, see Figure 1.

--- Insert Figure 1 about here ---

\subsection{Knowledge Characteristics prior to Transfer}

According to the conceptual model the internationalization knowledge acquired by a firm - in casu an MNC - can be categorized as either being tacit or explicit (Polanyi 1966, Nonaka/Takeuchi 1995). Tacit knowledge is hard to articulate with formal language since it is embedded in individual experience and involves intangible factors such as personal beliefs, perspectives and value systems (Nonaka/Takeuchi 1995). In contrast, explicit knowledge can be articulated in formal language (grammatical statements, mathematical expressions, specifications, etc.). This dichotomized categorization of knowledge is obviously an overt simplification inasmuch as most knowledge is not completely tacit or $100 \%$ explicit, but somewhere inbetween the two extremes, and will often consists of inseparable components with different characteristics. Furthermore, prior to its intra-organizational transfer some tacit knowledge may be subject to a partial or full conversion into explicit knowledge, i.e. the MNC that creates and/or acquires the internationalization knowledge engages in a process of 'codification' or 'articulation'.

\subsection{The Knowledge Transfer Process}

Firms can transfer knowledge across countries through a variety of different modes. For reasons of simplification our conceptual model only identifies two basically different mechanisms of knowledge transfer: 'Rich communication media' and 'written media'. These two transfer mechanisms constitute two extremes that presumably, in practice, rarely occur in pure forms. It is more likely that in most cases will the actual transfer of internationalization knowledge - the focal knowledge of this study - include both face-to-face communication and written media (Håkanson 2000). 
Rich communication media comprise face-to-face communication, informal interaction, and team based mechanisms (Daft 1986). This will require individual or team level visits, sharing of experience and face-to-face interaction or socialization (Nonaka 1987). Face-to-face interaction between individuals facilitates transfer of knowledge that is experienced-based, and permits interactive communication, questioning, flexibility, and adaptation (Daft/Huber 1987, Bresman et al. 1999). Almeida/Kogut (1996) show that transfer of people allow exploitation of experiential and tacit knowledge in new locations. Rich communication media also allow transfer of knowledge that the sender may be unaware of or is unable to express in a written media. Rich communications media are also suitable when partners need to adapt new, joint business practices. These adaptations may concern, for example, international differences in culture, laws, and business practices. Rich communication media are also more suitable for transferring 'holistic' type of knowledge, i.e. knowledge that requires facial expression and trust-creation between those who transmit knowledge and those who receive it (Huber 1991, Sharma 1998). However, transfer of knowledge through rich communication media is costly. Face-to-face communication is made difficult due to the involved travel costs, to dissimilar organizational cultures, and to language differences.

On the other extreme, knowledge can be transferred by written media, involving transfer based on manuals, data base development, written instructions, and blueprints. In comparison with rich communication media, manuals and other written media are less costly transfer mechanisms because limited individual level interaction is required and because the marginal costs of replicating written media are low. Accordingly, large companies, such as most MNCs, can achieve economies of scale when using written media. However, the more tacit and contextspecific the acquired knowledge, the less efficient is the use of written media.

On the face of it, the choice of transfer mechanism is closely related to the characteristics of the particular knowledge. We would expect 'rich communication media' to be the first choice of mechanism when the predominantly tacit knowledge is to be transferred across the organization, and 'written media' to be preferred as carrying mainly explicit knowledge. 
However, we submit that the choice of transfer mechanism is not completely given by the characteristics of the knowledge in a predetermined way. As indicated in Figure 1 'anomalies' may occur, i.e. explicit knowledge is transferred by use of rich communication media and tacit knowledge through written media. We consider the characteristics of knowledge and the transfer mechanism to be two logically separable issues. This approach contrasts the line of thinking in which the very characteristics of knowledge is defined by its eligibility to transfer from individual to individual and across organizations, see for example Johanson/Vahlne (1977) and Grant (1996). Instead we follow the line of Hedlund/Nonaka (1993) who distinguish between the storage of knowledge (as a stock), the transfer of knowledge (as a flow), and the transformation of knowledge (as interactions). In the same vein, we propose to logically disentangle the knowledge codification decision and the choice of transfer mechanism as two separate issues both open to managerial discretion.

This line of thinking leads us to the formulation of the following hypothesis:

$\mathrm{H}_{1} \quad$ Internationalization knowledge that is tacit/explicit when acquired will be transferred across the MNC organization through rich communication media/written media.

As indicated in Figure 1 different factors may facilitate or impede the knowledge transfer process in the MNC organization. Thus, the ease by which knowledge transfer is carried out is to some extent contingent on e.g. the specific organizational configuration of the MNC. From the literature review (sub-section 2.) we can extract at least three different factors. Two factors, 'transfer experience' and 'transfer capability' are related to the MNC configuration and affect the knowledge transfer process in a positive way. A third factor, 'psychic distance' is a mix of organizational and environmental subsets and is supposed to impede the knowledge transfer process of MNCs. Therefore, we need to control for these variables when testing for the performance implications of the fit between knowledge characteristics and transfer mechanism. 


\subsection{The Performance of MNC Knowledge Transfer}

The performance of knowledge transfer is contingent on internal and external factors that facilitate or inhibit the knowledge transfer process, such as transfer experience, transfer capability, and psychic distance. The facilitators and inhibitors represent situational characteristics usually exogenous to the management of the MNC organization. In most instances, the opportunity to control or manipulate these factors is, at best, limited and indirect. In contrast, MNC managers are themselves responsible for the effectuation of a proper fit between knowledge characteristics and transfer mechanisms, and this fit has performance implications as well.

Potentially, the knowledge transfer costs can be substantial. In Teece's seminal study (1977) of knowledge transfer in relation to international projects he estimated the transfer costs to vary from 2 per cent to 59 per cent of the total project costs. The costs involved are, first of all, derived from the efforts to codify and teaching complex knowledge to recipient MNC units (Kogut/Zander 1993). It is indeed likely that the difference between a successful and unsuccessful knowledge transfer is measurable on the financial bottom line of the MNC units involved in the transfer. Bresman et al. (1999) argue that even though financial performance for example revenue from jointly developed products - is a result of knowledge transfer, successful knowledge transfer is such an important prerequisite for satisfactory financial performance that it qualifies as a dependent variable in its own right.

Hence, we posit that an important success criterion of MNC knowledge transfer is the right fit between the characteristics of the acquired internationalization knowledge and the knowledge transfer mechanism used by the MNC.

Explicit knowledge is transferred most efficiently through written media, such as manuals and blueprints, because it will save the unnecessary communication costs associated with face-to-face communication. However, the use of written media for knowledge that is inherently tacit is likely to involve loss of knowledge. This is because not all knowledge in firms can be expressed in symbols and text. In their study of Disney Inc, Branen/Wilson (1996) found that Disney Inc in its internationalization process was unable to replicate its knowledge elsewhere. Due to the historical 
nature of the knowledge accumulation process the firm was not fully aware of all its knowledge. Hansen et al. (1999) submit that an important aspect of knowledge management is to find the right degree of codification and choose the proper knowledge transfer medium. Loss of strategic knowledge may be a result of 'exaggerated use' of written media. Garnished with anecdotal evidence the authors argue that sometimes firms do make unsuitable 'fits' with concomitant adverse performance consequences. Furthermore, as pointed out by Kogut/Zander (1993), codification and use of written media also increases the risk of dissemination of strategic, firmspecific knowledge to competitors. The potential knowledge loss when using written media is indicated by the dotted line in the lower, right-hand corner of Figure 1.

The knowledge loss - both internally and externally - is minimized when rich communication media are used. This transfer mechanism, however, incurs high communication costs. These costs are related to international travelling, rotation of personnel, meetings, etc. - confer the dotted line in the upper, right-hand corner of Figure 1. Therefore, MNCs should only use rich communication media with care, i.e. only when the internationalization knowledge is inherently tacit. The 'right fit' is between inherently tacit knowledge and rich communication media; a 'misfit' appears when more or less explicit internationalization knowledge is transferred by use of rich communication media - involving 'unnecessarily' high communication cost.

Hence, a trade-off between loss of knowledge on the one hand and high communication costs on the other hand confronts the MNC manager. Choosing the appropriate transfer mechanism is important if the MNC is to transfer knowledge efficiently. Therefore, we can formulate the following, second hypothesis:

$\mathrm{H}_{2} \quad$ Performance of transfer is maximized when tacit internationalization knowledge is transferred across the MNC organization through rich communication media and explicit knowledge by written media.

Figure 2 illustrates, in a simple two-by-two matrix, the logic of the hypothesis on 'fits' and 'misfits' between knowledge characteristics and the transfer mechanisms. 


\section{Empirical Analysis}

\subsection{Data}

The data of the study were gathered through a mail survey carried out in Denmark. The database 'CD-Direct' was used to identify Danish firms with (1) international operations, (2) more than 20 employees. Firms complying with these two criteria were supposed to be involved in some transfer of internationalization knowledge. The Danish population of such firms comprised 723 units that varied greatly in terms of size, industry (both manufacturing and service firms were included), and geographical location of their international operations. In August 1998 the questionnaire was sent out to identifiable company informants - primarily managing directors in the 723 firms. Most questionnaires were completed by the managing director or another top executive. A reminder was mailed one month after the initial mailing. Upon this follow-up procedure the number of replies reached 246, corresponding to a 34 per cent response rate. For various reasons (e.g. the closing-down of foreign business activities) a number of returned questionnaires were not usable. After exclusion of incomplete questionnaires a total of 198 replies - making up a net response rate of 27.4 per cent - was usable for data processing. A test was conducted to check the sample for non-response bias. Regarding size and number of foreign subsidiaries no statistically significant differences between respondents and non-respondents were found.

An average profile of the firms in the sample is shown in Table 1. The average turnover of the sample firms was DKK 238,000,000 (equivalent to US \$28,000,000). The average number of employees was 192 including personnel in Denmark and abroad. But as reflected by the standard deviations in Table 1 the variation in terms of firm size is considerable. One seventh of the personnel was employed outside Denmark and almost one half of the average turnover is generated outside the home country.

--- Insert Table 1 about here ---

The average firm is fairly internationalized and possesses considerable experience in conducting foreign operations (21 years). However, the sample includes also a group of 'novice' exporters. 


\subsection{Operationalization of Variables}

The identified company informants, i.e. mostly the managing directors, were asked to select one recent international business assignment, such as the entry of a new foreign market or a considerable expansion of an exiting international business. The respondent should consider the chosen business assignment to be important for the continued international expansion of the firm. Furthermore, the selected business assignment should, preferably, be well underway; that is, the company should already be involved in business in the foreign location. Given this focus, the company informants were asked to indicate the amount and character of the internationalization knowledge required for the particular business assignment.

Following Erikson et al. (1997) internationalization knowledge is of three different kinds: Institutional knowledge on the host country, knowledge on counterparts in the host country and organizational knowledge on managing foreign operations. All three kinds of internationalization knowledge are required to conduct foreign activities. Furthermore, each of these three kinds of internationalization knowledge is divided into 6-7 items - or, as we label them, knowledge components. The characteristics of the internationalization knowledge as acquired and the knowledge transfer mechanisms were then assessed for the twenty internationalization knowledge components. The knowledge components are listed in Table 2. Altogether the twenty components make up internationalization knowledge of firms.

\section{--- Insert Table 2 about here ---}

The characteristics of knowledge was measured by asking the company informants to indicate for the individual internationalization knowledge component to what extent the knowledge needed for the particular assignment was acquired through own, practical experience or via purchase of external expertise. Thereby, the respondents indicated tacitness or explicitness, respectively, of the acquired internationalization knowledge. Furthermore, for each knowledge component the company informant was asked to indicate the characteristics of knowledge on a 7-point Likert scale. The Likert scale went from 1 (= own practical experience) to 7 (= purchase of external expertise). 
The applied mechanism of knowledge transfer was measured in a similar way by asking the company informants to indicate to what extent internationalization knowledge for the particular foreign assignment was transferred across the organization through daily face-to-face communication (proxy for 'rich communication media') or via company manuals, reports, or other written media. For each of the twenty internationalization knowledge components the respondents were asked to give their indication on a 7-point Likert scale going from 1 (= daily face-to-face communication) to 7 (= company manuals, reports or other written media).

The performance of the knowledge transfer was measured as the company informant's perception of the overall satisfaction with the particular foreign assignment on a 7-point Likert scale (ranging from $1=$ no gains, to $7=$ substantial gains). The assumption is that this perceptual performance variable captures the various dimensions of performance (discussed in the subsection 3.3), including knowledge loss and high communication costs.

Furthermore, three control variables are included in the model reflecting facilitators and deterrents of knowledge transfer that have been identified in the literature (see sub-section 2.). The three control variables are: (1) transfer experience (measured on a 7-point Likert scale as international experience of adapting products to foreign markets), (2) transfer capability (measured on a 7-point Likert scale as level of routines for modification of business procedures to fit foreign market conditions), and (3) psychic distance (measured on a 7-point Likert scale as the perception of distance to the foreign location of the business assignment in question).

Two additional control variables are included: (4) the characteristics - when acquired - of the particular internationalization knowledge, and (5) the mechanism of transferring the particular knowledge.

\subsection{Results}

Descriptive data on the variables and a correlation matrix is shown in an appendix.

The hypothesis 1 is proposing a relationship between the characteristics of the internationalization knowledge as acquired and the applied transfer mechanism. Tacit 
internationalization knowledge is hypothesized to be transferred mainly through rich communication media and explicit internationalization knowledge mainly by written media. The tests of hypothesis 1 is conducted by estimating the correlation coefficients of the variation between, on the one hand, knowledge characteristics of the particular internationalization knowledge component (i.e. tacitness versus explicitness) and, on the other hand, the mechanism used for transferring this particular internationalization knowledge component (i.e. rich communication media versus written media). Following the hypothesis the correlation coefficients are expected to be significantly positive. The coefficients are shown in Table 2 (last column). Eighteen out of the twenty coefficients are, as expected, significantly positive. All in all, this gives strong support for the hypothesis saying that internationalization knowledge acquired as tacit knowledge will be transferred mainly by rich communication media, while explicit internationalization knowledge is transferred primarily through written media.

However, the coefficients vary from 0.15 to 0.46 indicating that the relationships between knowledge characteristics and transfer mechanism are far from being unambiguous. In other words, the mechanism of knowledge transfer is not exclusively given by the characteristics of the internationalization knowledge in a pre-determined way. Although there is an association between the characteristics of the knowledge and the transfer mechanism as expected, a substantial number of company managers did indicate unorthodox combinations of knowledge characteristics and transfer mechanisms: either they transferred tacit knowledge by written media or they transferred explicit knowledge through rich communication media. In order to further examine this relationship we split the characteristics of knowledge and the transfer mechanisms into two groups (values 1-3 and values 4-7 on the Likert scales). Then we look at the relationships for all the twenty internationalization knowledge components pertaining to the 198 sample firms (i.e. $20 \times 198=3,960$ relationships). We then divide all the relationships into a twoby-two matrix along the same lines as in Figure 2. This is done in Figure 3.

\section{--- Insert Figure 3 about here ---}

As shown in Figure 3, most relationships follow the predicted pattern (quadrant 1 and 4). Of the 3,960 relationships in total 1,307 relationships follow the pattern proposed in hypothesis 1 
(corresponding to 33 per cent of all relationships). Thus, tacit internationalization knowledge is transferred mainly through rich communication media. 1,303 relationships (32.9 per cent) follow the pattern predicted in hypothesis 1 (explicit internationalization knowledge is mainly transferred by written media). This means that two thirds of the relationships follow the predicted dominant pattern. Still, there is a substantial proportion - one third - of the relationships that follows different patterns. In 721 relationships (corresponding to 18.2 per cent) the tacit internationalization knowledge is transferred by written media, and in 630 cases the explicit internationalization knowledge is transferred by rich communication media. All in all, these figures confirm hypothesis 1 in so far as the hypothesis also predict a significant number of 'exceptions' to the general rule of fit between knowledge characteristics and transfer mechanisms. Still, a strong reservation should be kept in mind as regards the observation of seemingly tacit internationalization knowledge being transferred through written media. Our empirical research design does not take into account the possibility of codification of tacit internationalization knowledge prior to transfer. In other words, since we did not investigate to what extent the firms carried out transformation of tacit knowledge a great deal of the 721 observations may in fact be explicit - and not tacit - internationalization knowledge transferred through written media. Because of this shortcoming in our research design we may very well overestimate the number of 'misfits'.

Our variables for characteristics of knowledge is constructed so low values indicate tacit knowledge while high values indicate the characteristics of explicit knowledge. Similarly, the variables of transfer mechanism are indicating rich communication media for low values and written media for high values. In the case of 'fits' as discussed above both values will either be low (tacit knowledge transferred by rich communication media) or high (explicit knowledge transferred by written media). So, for the product of the two variables the fit combinations are expected to lie in both ends of the scale, while the non-fit combinations are expected to lie inbetween. Therefore, following hypothesis 1 on the performance fit we expect a U-shaped relationship between 'performance' on the one side and the interaction term of knowledge characteristics and transfer mechanism on the other side. In order to test this we apply the following model: 
Performance $=f\left(\right.$ knowledge $*$ transfer mechanism, $(\text { knowledge } * \text { transfer mechanism })^{2}$, controls $)$

Hence, the model includes the interaction term of the characteristics of internationalization knowledge and the transfer mechanism in first and second order.

Following hypothesis 2 we expect the interaction term of first order to be significantly negative. Conversely, the interaction term of second order is expected to be significantly positive. This indicates that performance will increase both in the low and high ends of the scale - the intervals of observed combinations where the characteristics of knowledge and the transfer mechanisms fit together.

--- Insert Table 3 about here ---

The model was conducted for the twenty knowledge components and with the performance variable - twenty different models in total. However, Table 3 shows the results where all the twenty knowledge components are added together into one single variable (with Cronbach alpha $=0.89$ for knowledge characteristics and Cronbach alpha $=0.92$ for transfer mechanisms). Table 3 only includes the results of a regression analysis where all the twenty knowledge components are collapsed into one single variable. More rigorous analyses were conducted for all the twenty knowledge components, but the results are not shown. Furthermore, as the dependent variable is measured on a 7 point Likert scale and there is some controversy on whether this can be interpreted as interval data (see for example Nunally 1978) we have also conducted a logistic regression model (prog logistic) with ordinal responses (SAS 1991). The results turned out to be almost identical with the ones obtained by use of the ordinary regression model. The results of the alternative regression model confirm the reliability of our model.

As can be seen in Table 3, the interaction term of first order is significantly negative and that of second order is significantly positive (both on $5 \%$ significance level). The same picture holds when looking at the similar regression analyses for the individual knowledge components. 
All control variables appeared to affect performance significantly (on 5 and 10 per cent levels). Transfer experience, transfer capability and psychic distance came out with the expected signs. Somewhat surprisingly, however, the characteristics of knowledge and the transfer mechanism did not only appear to have an effect on performance in interaction, but also as independent variables. On a 10 per cent significance level performance is associated in a positive way with explicit internationalization knowledge and written media.

As significant problem with this test might be that the data has a self-selection bias in the sense that managers are aware of the performance implications of their choices. This is violating the assumption (in the regression analysis) that the dependent variable (performance) should not be determined by the same factors as the independent variable (choice of transfer mechanism). In order to correct for this self-selection bias we have run the Heckman two stage regression procedure (Heckman 1979). The results turn out to be very similar with the first order effect of the interaction between knowledge characteristics and transfer mechanism being significantly negative and the second order effect being positively significant (as in the OLS-model).

\section{Conclusions and Managerial Implications}

For a long time theories on the existence and growth of MNCs and on the internationalization process of firms either assumed an almost frictionless intra-organizational knowledge transfer process, or considered the crucial internationalization knowledge to be extremely contextspecific, thereby making the transfer process more or less futile. Hence, the knowledge transfer process was hardly an issue in the early versions of these theories. Since then, IB scholars have inspired by organizational learning literature - gradually adopted a less deterministic and more sophisticated view on the knowledge transfer processes of MNCs: Transfer of knowledge within the multinational organization is neither frictionless or futile and requires a great deal of managerial discretion.

In this study we have examined the choice of mechanisms for transferring internationalization knowledge across multinational organizations. In a somewhat simplified decision matrix we 
would - on the face of it - expect tacit internationalization knowledge to be transferred through rich communication media and explicit knowledge through written media. Empirical evidence of Danish MNCs shows that most - but far from all - transfers of internationalization knowledge follow the expected pattern. Hence, up to one third of the observed combinations may be described as mismatches of knowledge characteristics and transfer mechanisms. The data indicate that to some extent are these mismatches associated with impaired performance as perceived by the MNC managers involved in the foreign business assignment. These findings send a warning signal to MNC managers to show a great deal of vigilance in their choice of knowledge transfer mechanisms. ${ }^{1}$

${ }^{1}$ The authors would like to thank Peter Buckley, Ivo Zander and Udo Zander for their valuable comments and suggestions to an earlier version of the paper. 


\section{References}

Adler, N., International Dimensions of Organizational Behaviour (2 ${ }^{\text {nd }}$ ed.), Boston: PWS Kent, 1995.

Aharoni, Y, The Foreign Investment Decision Process, Boston: Harward Business School, 1966.

Almeida, P./Kogut, B., The Exploration of Technological Diversity and the Geographic

Localization of Innovation, Small Business Economics, 9, 1996, pp. 21-31.

Argote, L., Organizational Learning: Creating, Retaining and Transferring Knowledge, Boston:

Kluwer Academic Publishers, 1999.

Bartlett, C.A./ Ghoshal, S., Managing Across Borders: the Transnational Solution, Boston:

Harvard Business School Press, 1989.

Bilkey, W. J./Tesar, G., The export behaviour of smaller sized Wisconsin manufacturing firms, Journal of International Business Studies, 8(1), 1977, pp. 93-98.

Branen, M./Wilson, J., Recontextualization and internationalization: Lessons in Transcultural Materialism from the Walt Disney Company, CEMS Business Review, 3(March), 1996.

Bresman, H./Birkinshaw, J./Nobel, R., Knowledge Transfer in International Acquisitions, Journal of International Business Studies. 30(3), 1999, pp. 439-62.

Carlson, S., How Foreign is Foreign Trade? A Problem in International Business Research, Uppsala: Uppsala University Press, 1975..

Cyert, R. D./March, J.G., A Behavioural Theory of the Firm, Englewood Cliffs, NJ: PrenticeHall, 1963. 
Daft, R.L., Organizational Information Requirements, Media Richness and Structural Design, Management Science, 32 (May), 1986.

Daft R.L./Huber. G.P., How Organizations Learn: A Communication Framework, Research in Sociology of Organizations, 5, 1987, pp. 1-36.

Davidson, W.H., D.G. McFetridge. 1985. Key characteristics in the choice of international technology transfer mode. Journal of International Business Studies 16(2) 5-21.

de Meyer, A. 1991. Tech Talk: How Managers Are Stimulating Global R\&D Communication. Sloan Management Review 32(Spring) 49-58.

Epple, D./Argote, L./Murphy, K., An Empirical investigation of the micro structure of knowledge acquisition and transfer through learning by doing, Operations Research, 44, 1996, pp. 77-86.

Erikson, K., J. Johanson, A. Majgård, D. Sharma. 1997. Experiential knowledge and cost in the internationalization process. Journal of International Business Studies 28(2).

Forsgren, M., J. Johanson. 1992. Managing Internationalization in Business Networks. In Forsgren, M., J. Johanson (eds). Managing networks in International Business, Gordon and Breach, Philadelphia.

Galbraith, C.S. 1990. Transferring core manufacturing technologies in high technology firms. California Management Review 32(4) 56-70.

, H. Korine, G. Szulanski. 1994. Interunit communication in multinational corporations. Management Science 40(1) 96-111.

Grant, R. M. 1996. Toward a Knowledge-based Theory of the Firm. Strategic Management Journal 17(Special Issue) 109-22. 
Gupta, A.K., V. Govindarajan. 1991. Knowledge flows and the structure of control within multinational corporations. Academy of Management Review 16 768-792.

Hansen, M., N. Nohria, T. Tierney. 1999. What's your strategy for managing knowledge? Harvard Business Review 77 (March-April) 106-116.

Hedlund, G. 1986. The hypermodern MNC - a heterarchy? Human Resource Management 25(1) 9-36.

. 1994. A Model of Knowledge Management and the N-Form Corporation. Strategic Management Journal 15(2) 73-90.

., I. Nonaka. 1993. Models of knowledge management in the West and Japan. In Lorange, P., B. Chakravarthy, J. Roos, A. Van de Ven (eds). Implementing strategic processes: Change, learning and co-operation. Blackwell, London

Hofstede, G. 1984. Culture's Consequences: International differences in work related values. Sage Publications, Beverly Hills, CA.

Huber, G. P. 1991. Organizational learning: The contributing processes and the literature. Organization Science 2(1) 88-115.

Håkanson, L. 2000. From Tacit Knowledge to Scientific Theory: The Power and Logic of Articulation. Competitive Paper presented at the EIBA $26^{\text {th }}$ Annual Conference in Maastricht, December 10-12, 2000.

Johanson, J., J.-E. Vahlne. 1977. The internationalization process of the firm - A model of knowledge development and increasing foreign market commitments. Journal of International Business Studies 8(1) 23-32. 
Keegan, W.J. 1974. Multinational Scanning: A study of the Information Sources Utilized by Headquarters Executives in Multinational Companies. Administrative Science Quarterly 19 (3) 411-421.

Kogut, B. , U. Zander. 1992. Knowledge of the firm, combinative capabilities, and the replication of technology. Organization Science 3(3) 383-397.

., U. Zander. 1993. Knowledge of the firm and the evolutionary theory of the multinational corporation. Journal of International Business Studies 24(4) 625-46.

Lester, R.K., M.J. McCabe. 1993. The effect of industrial structure on learning by doing in nuclear power plant operation. The Rand Journal of Economics 24 418-438.

Mowery, D. C., E.O. Hoanne, B.S. Silverman. 1996. Strategic Alliances and Inter-Firm Knowledge Transfer. Strategic Management Journal 17: 77-91.

Nonaka, I. 1987. Managing the firm as an information creation process. , H. Takeuchi. 1995. The Knowledge-Creating Company. Oxford University Press, Oxford.

Nunnally, J. 1978. Psychometric Theory. McGraw-Hill, NY.

Penrose, E. 1959. The Theory of the Growth of the Firm. Basil Blackwell, London.

Polanyi, M. 1966. The Tacit Dimension. Doubleday, Garden City, NY

SAS. 1991. SAS/STAT User's Guide, Release 6.03 Edition. SAS Institute Inc, Cary, NC.

Sharma, D. 1998. A Model for Governance in International Strategic Alliances. Journal of Business \& Industrial Marketing 13(6) 511-528. 
Simonin, B.L. 1999. Transfer of Marketing Know-How in International Strategic Alliances: An Empirical Investigation of the Role and Antecedents of Knowledge Ambiguity. Journal of International Business Studies 30(3) 463-90.

Szulanski, G. 1996. Exploring internal stickiness: Impediments to the transfer of best practice within the firm. Strategic Management Journal 17: 27-43.

Teece, D.J. 1977. Technology Transfer by Multinational Firms: The Resource Cost of Transferring Technological Know-how. Economic Journal, 87: 242-61.

Zander, U. 1991. Exploiting a Technological Edge: Voluntary and Involuntary Dissemination of Technology. Doctoral dissertation. Institute of International Business, Stockholm.

, B. Kogut. 1995. Knowledge and the Speed of the Transfer and Imitation of Organizational Capabilities. Organization Science 6(1) 76-92. 

Figure 1 Conceptual model of the study (with indication of hypotheses)

KNOWLEDGE CHARACTERISTICS

PERFORMANCE

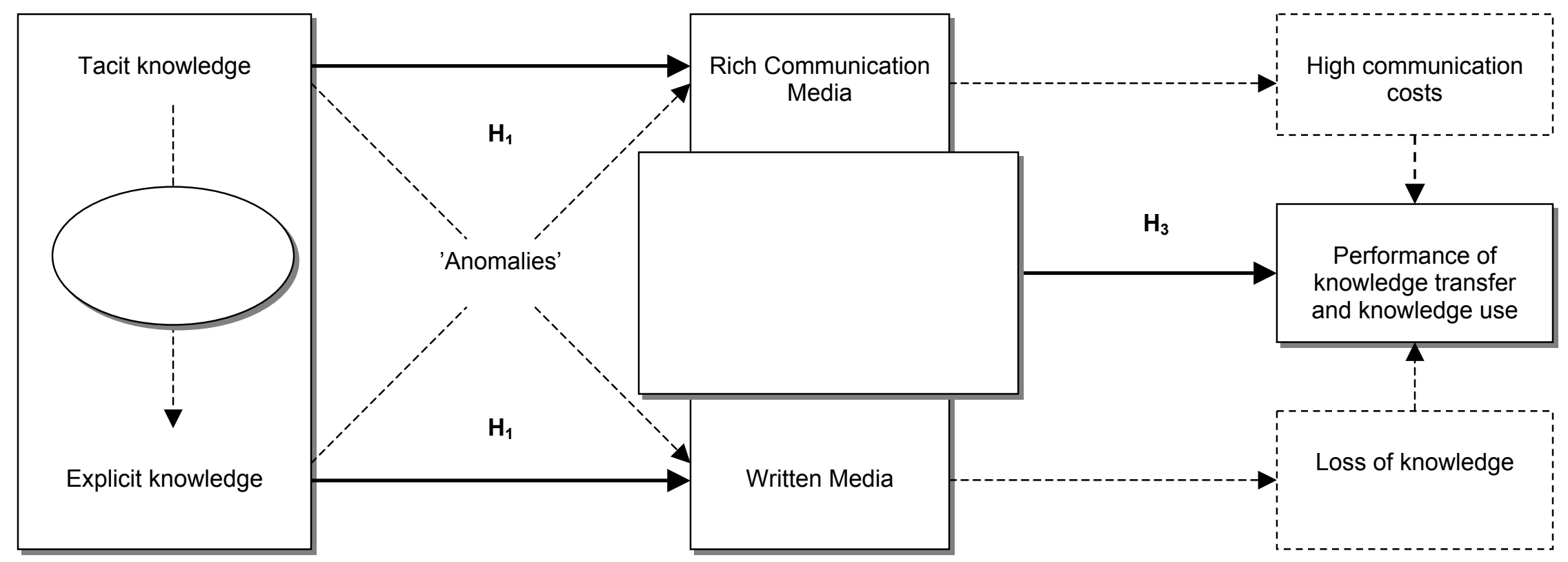


Figure 2 Performance (mis)fit between knowledge characteristics and knowledge transfer mechanisms

\begin{tabular}{|c|c|c|}
\hline KNOWLEDGE CHARACTERISTICS • & \multicolumn{2}{|c|}{ Tacit } \\
\hline RRANSFER MECHANISM - & FIT & $\begin{array}{c}\text { MISFIT } \\
\text { (High communication costs) }\end{array}$ \\
\cline { 2 - 3 } Written media & $\begin{array}{c}\text { MISFIT } \\
\text { (Knowledge loss) }\end{array}$ & FIT \\
\hline
\end{tabular}


Table 1. Characteristics of the sample $(N=198)$

\begin{tabular}{|l|c|c|}
\hline \multicolumn{1}{|c|}{ Company characteristics (1998) } & Mean & Standard deviation \\
\hline $\begin{array}{l}\text { Total turnover (million DKK) } \\
-\quad \% \text { of sales abroad }\end{array}$ & $\begin{array}{c}238 \text { (US \$ 28 million) } \\
42.9\end{array}$ & $\begin{array}{c}488 \text { (US \$ 57 million) } \\
31.2\end{array}$ \\
\hline $\begin{array}{l}\text { Total number of employees } \\
\text { \% employed overseas }\end{array}$ & 192 & 419 \\
& 14 & 17 \\
$\begin{array}{l}\text { Number of foreign countries } \\
\text { in which the company operates }\end{array}$ & 18 & 18 \\
\hline Years of export experience & 21 & \\
\hline
\end{tabular}


Table 2. Correlation between knowledge characteristics and transfer mechanisms for various internationalization knowledge components

\begin{tabular}{|c|c|c|c|c|}
\hline$\checkmark$ Intern & tionalization Knowledge components $\checkmark$ & $\begin{array}{c}\text { Knowledge } \\
\text { Characteristics } \\
\text { Tacit-Explicit }\end{array}$ & $\begin{array}{c}\text { Transfer } \\
\text { Mechanism } \\
\text { Rich-Written }\end{array}$ & \\
\hline & & Mean & Mean & $\begin{array}{l}\text { Correlation } \\
\text { coefficients }\end{array}$ \\
\hline $\begin{array}{l}\text { Institutional } \\
\text { knowledge } \\
\text { about host } \\
\text { country in } \\
\text { terms of ... }\end{array}$ & $\begin{array}{ll}\text { 1. } & \text { Technology standards } \\
\text { 2. } & \text { Laws on products and quality standards } \\
\text { 3. } & \text { Business legislation } \\
\text { 4. } & \text { Financial practice and currency rules } \\
\text { 5. } & \text { Business culture } \\
\text { 6. } & \text { Infrastructure } \\
\text { 7. } & \text { Structure of industry }\end{array}$ & $\begin{array}{l}2.54 \\
3.19 \\
3.63 \\
3.17 \\
2.43 \\
2.80 \\
2.86\end{array}$ & $\begin{array}{l}3.50 \\
3.86 \\
3.41 \\
3.42 \\
2.35 \\
2.73 \\
2.77\end{array}$ & $\begin{array}{l}-0.10 \\
0.02 \\
0.16^{* *} \\
0.22^{* * *} \\
0.15^{* *} \\
0.22^{* * *} \\
0.22^{* * *}\end{array}$ \\
\hline $\begin{array}{l}\text { Business } \\
\text { knowledge } \\
\text { about ... }\end{array}$ & $\begin{array}{l}\text { 8. Customers in Denmark } \\
\text { 9. Customers abroad } \\
\text { 10. Suppliers in Denmark } \\
\text { 11. Suppliers abroad } \\
\text { 12. International organizations } \\
\text { 13. Authorities abroad }\end{array}$ & $\begin{array}{l}2.12 \\
2.35 \\
2.39 \\
2.54 \\
3.32 \\
3.82\end{array}$ & $\begin{array}{l}2.66 \\
2.84 \\
2.72 \\
2.85 \\
3.20 \\
3.40\end{array}$ & $\begin{array}{l}0.30^{* * *} \\
0.34^{* * *} \\
0.46^{* * *} \\
0.35^{* * *} \\
0.36^{* * *} \\
0.33^{* * *}\end{array}$ \\
\hline $\begin{array}{l}\text { General } \\
\text { internatio- } \\
\text { nalization } \\
\text { knowledge } \\
\text { about ... }\end{array}$ & $\begin{array}{l}\text { 14. Human resource management abroad } \\
\text { 15. Financing abroad } \\
\text { 16. Development \& adaptation of products } \\
\text { 17. Development \& adaptation of production } \\
\text { 18. Making business with new customers } \\
\text { 19. Making business on new markets } \\
\text { 20. Collaboration with other companies }\end{array}$ & $\begin{array}{l}2.48 \\
3.48 \\
2.18 \\
2.36 \\
2.15 \\
2.37 \\
2.61\end{array}$ & $\begin{array}{l}2.57 \\
3.29 \\
2.93 \\
2.98 \\
2.59 \\
2.61 \\
2.72\end{array}$ & $\begin{array}{l}0.40^{* * *} \\
0.39^{* * *} \\
0.27^{* * *} \\
0.19^{* * *} \\
0.23^{* * *} \\
0.32^{* * *} \\
0.41^{* * *}\end{array}$ \\
\hline
\end{tabular}

Note: ${ }^{* * *},{ }^{* *}$ and ${ }^{*}$ indicates $1 \%, 5 \%$ and $10 \%$ level of significance, respectively. 
Figure 3 Distribution of performance (mis)fits of the sample

\begin{tabular}{|c|c|c|}
\hline KNOWLEDGE CHARACTERISTICS • & Tacit & \\
TRANSFER MECHANISM - & \multicolumn{2}{|c|}{ Explicit } \\
\hline \multirow{2}{*}{ Rich communication media } & 1,307 & 630 \\
& $(33.0 \%)$ & $(15.9 \%)$ \\
Written media & & 1,303 \\
& & $(32.9 \%)$ \\
\hline
\end{tabular}


Table 3. Regression analysis of the hypothesized model

\begin{tabular}{|c|c|}
\hline & Performance \\
\hline Intercept & $\begin{array}{l}2.68^{* * *} \\
(0.86)\end{array}$ \\
\hline Knowledge Characteristics *: Transfer Mechanism & $\begin{array}{l}-0.39^{* *} \\
(0.19)\end{array}$ \\
\hline (Knowledge Characteristics 决 Transfer Mechanism) ${ }^{2}$ & $\begin{array}{c}0.15^{\star *} \\
(0.07)\end{array}$ \\
\hline Transfer Experience & $\begin{array}{l}0.68^{*} \\
(0.35)\end{array}$ \\
\hline Transfer Capability & $\begin{array}{l}0.01^{* *} \\
(0.005)\end{array}$ \\
\hline Psychic Distance & $\begin{array}{l}-0.07^{*} \\
(0.04)\end{array}$ \\
\hline $\begin{array}{l}\text { Knowledge Characteristics as Acquired } \\
\text { (Tacit - Explicit) }\end{array}$ & $\begin{array}{l}0.59^{*} \\
(0.31)\end{array}$ \\
\hline $\begin{array}{l}\text { Transfer Mechanism } \\
\text { (Rich Communication Media - Written Media) }\end{array}$ & $\begin{array}{l}0.14^{* *} \\
(0.008)\end{array}$ \\
\hline $\begin{array}{l}\text { F-value } \\
\mathrm{N} \\
\text { R-square }\end{array}$ & $\begin{array}{l}3.20^{* * *} \\
198 \\
11.1 \%\end{array}$ \\
\hline
\end{tabular}

${ }^{* * *},{ }^{* *}$, and ${ }^{*}$ indicates $1 \%, 5 \%$ and $10 \%$ level of significance, respectively. 
APPENDIX: Correlation matrix

$\begin{array}{llllllll}1 & 2 & 3 & 4 & 5 & 6 & 7 & 8 \\ 1.00 & & & & & & & \\ -0.04 & 1.00 & & & & & & \\ 0.05 & 0.31^{* * *} & 1.00 & & & & & \\ 0.0003 & 0.78^{* * *} & 0.79^{* * *} & 1.00 & & & & \\ 0.03 & 0.72^{* * *} & 0.72^{* * *} & 0.96^{* * *} & 1.00 & & & \\ 0.21^{* * *} & -0.10 & 0.14^{* *} & 0.03 & 0.04 & 1.00 & & \\ 0.23^{* * *} & -0.18^{* *} & 0.08 & -0.08 & -0.11 & 0.24^{* * *} & 1.00 & \\ -0.13^{*} & 0.08 & -0.05 & -0.0001 & -0.01 & -0.02 & -0.06 & 1.00 \\ & & & & & & & \\ 5.26 & 2.71 & 2.97 & 8.36 & 89.6 & 5.40 & 5.67 & 3.58 \\ 1.26 & 0.93 & 1.07 & 4.46 & 86.5 & 1.32 & 1.64 & 2.21\end{array}$

